\title{
Effectiveness of computerized motion-based cognitive rehabilitation on improvement of working memory of children with ADHD
}

\author{
Fatemeh Jalili $^{1}$, Vahid Nejati ${ }^{2}$ Hasan Ahadi ${ }^{3}$, Seyed Ali Katanforosh ${ }^{4}$ \\ ${ }^{I}$ Department of General Psychology, Science and Research Branch, Islamic Azad University, Tehran, Iran \\ ${ }^{2}$ Associate Professor, Department of Psychology, Faculty of Education and Psychology, Shahid Beheshti University, \\ Tehran, Iran \\ ${ }^{3}$ Professor ,Department of Psychology, Faculty of Psychology and Educational Sciences, Allameh Tabataba'i University, \\ Tehran, Iran \\ ${ }^{4}$ Assistant Professor,Department of Computer Sciences, Faculty of Mathematical Sciences, Shahid Beheshti \\ University, Tehran, Iran
}

\begin{abstract}
Background: Attention deficit and hyperactivity disorder (ADHD) is a neurodevelopmental disorder. Deficit of executive functions is the main feature of ADHD which has negative outcomes on the affected children. The purpose of the current study was to determine the effectiveness of computerized motion-based cognitive rehabilitation on improvement of executive function, and working memory of children with ADHD.

Materials and methods: The research method was semi-experimental with pre-test and post-test design with control group which was done on 28 ADHD children with age of 8-12 years old in Karaj city using a purposeful sampling method. The samples were allocated randomly into two control and intervention groups. $\mathrm{N}$-Back test was used to assess the working memory. Data were analyzed with repeated mixing variance analysis and using SPSS.ver20.

Results: The result of the study showed that working memory improved with cognitive rehabilitation through exercise (CORTEX) $(\mathrm{P}<0.01)$.

Conclusion: This study showed that computerized motion-based cognitive rehabilitation can improve working memory of children with ADHD

Keywords: Attention Deficit and Hyperactivity Disorder (ADHD), Computerized motion-based cognitive rehabilitation, Working memory.

Cited as: Jalili F, Nejati V, Ahadi H, Katanforosh SA. Effectiveness of computerized motion-based cognitive rehabilitation on improvement of working memory of children with ADHD. Medical Science Journal of Islamic Azad University, Tehran Medical Branch 2019; 29(2): 171-180.
\end{abstract}

Correspondence to: Vahid Nejati

Tel: +989121888062

E-mail: nejati@sub.ac.ir

ORCID ID: 0000-0002-5338-7099

Received: 9 Sep 2018; Accepted: 10 Nov 2018 
مجله علوم يزشكى دانشعاه آزاد اسلامى

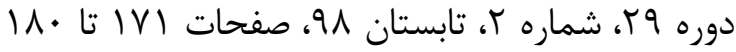

\section{اثربخشى توانبخشى شناختى رايانهاى مبتنى بر حركت در بهبود حافظه كارى كودكان مبتلا به اختلال نقص توجه و بيش فعالى

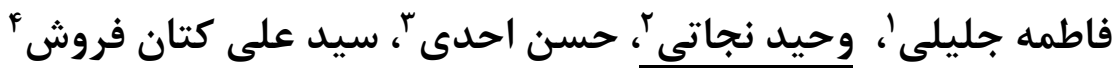

' كروه روانشناسى عمومى، دانشكده علوم انسانى، دانشكاه آزاد اسلامى واحد علوم و تحقيقات، تهران، ايران

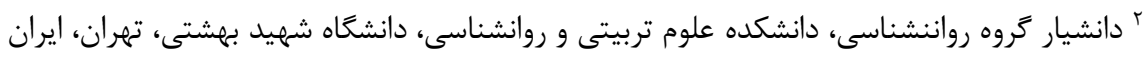

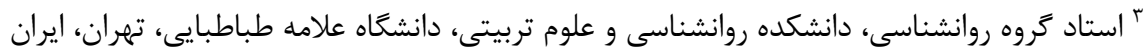

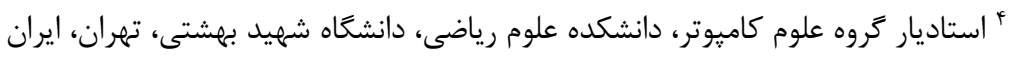

جكبده

سابقه و هدف: اختلال نقص توجه و بيش فعالى، اختلالى عصب تحولى است. نقص كاركردهاى اجرايى خصيصه فراكير /ين اختلال

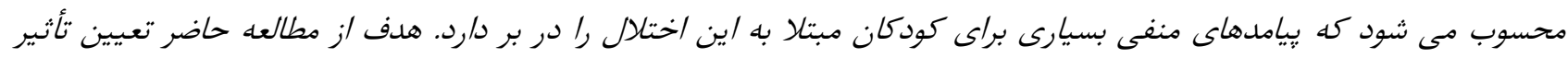

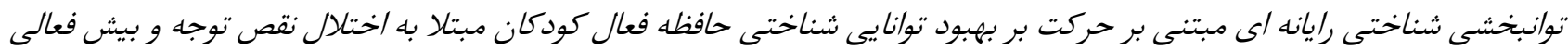

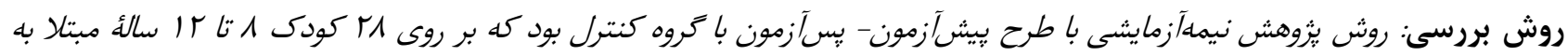

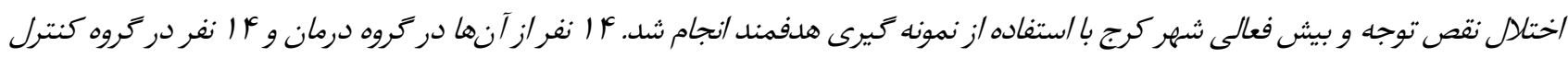

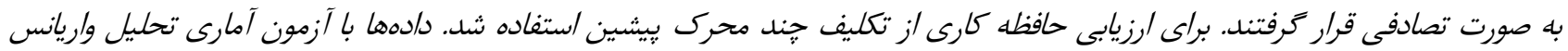

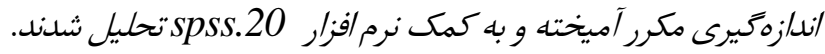

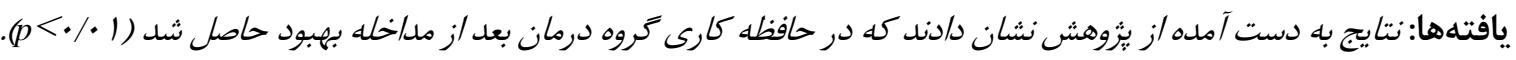

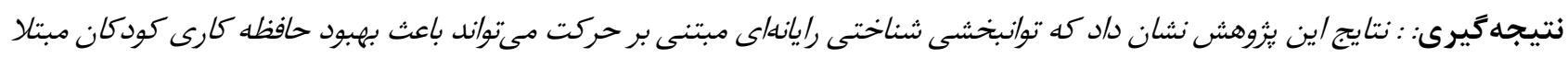

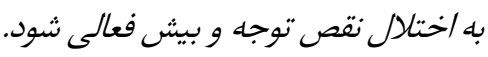
وازگكان كليدى: اختلال نقص توجه و بيش فعالى، توانبخشى شناختى رايانهاى (مبتنى بر حركت)، حافظه كارى.

بسيارى از دانشآموزان مشكلات خشمغيرى ايجاد مى كنــد و مقدمه

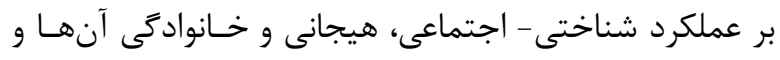

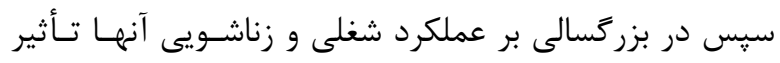

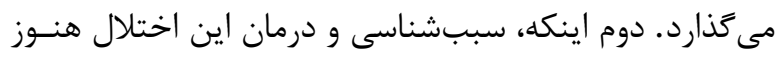

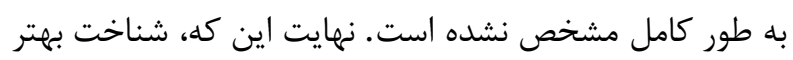

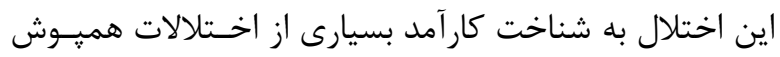

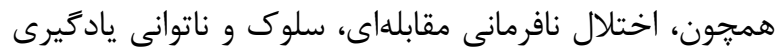

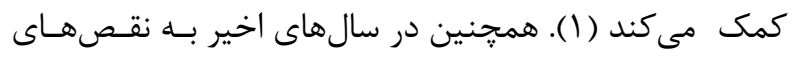

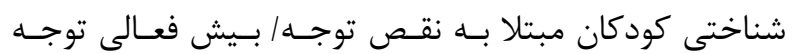
امروزه اختلال نقص توجه/ بيش فعالى به دلايل كوناكون مورد

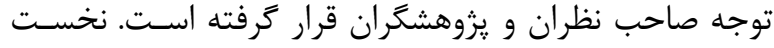

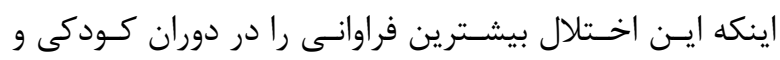

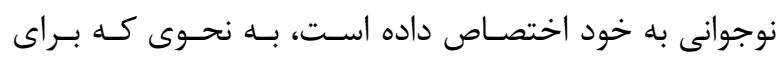


بيش حركتى مبتلايان به اخـتلال نقـص توجـهـ/ بــيش فعـالى إلى

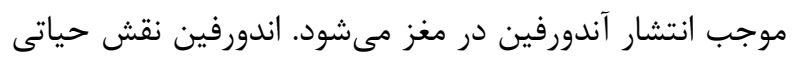

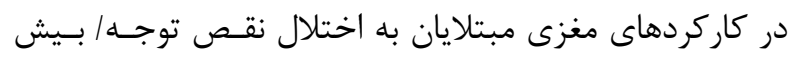

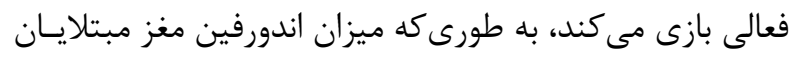

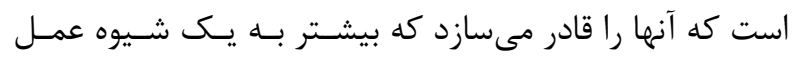

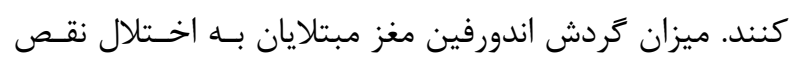
توجه/ بيش فعالى كمتر از افراد عادى است و يكى از از اقـدامات

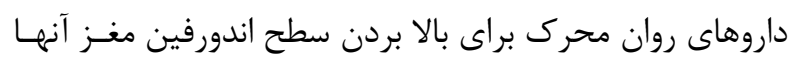

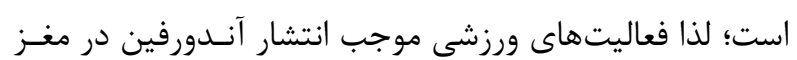

مىشوند (ب ا).

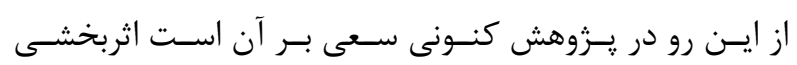

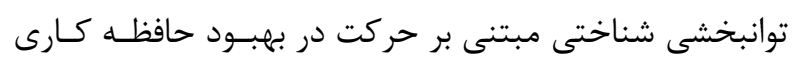

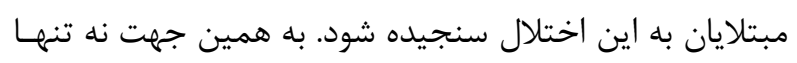

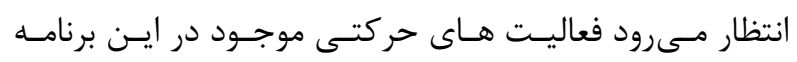

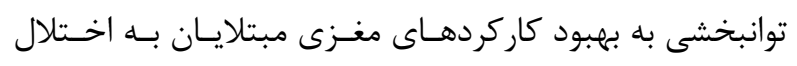

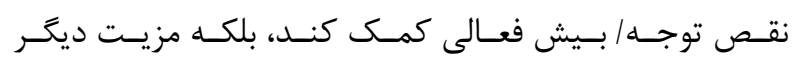

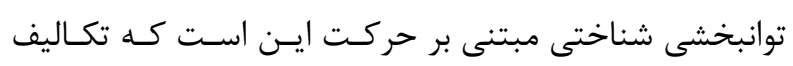

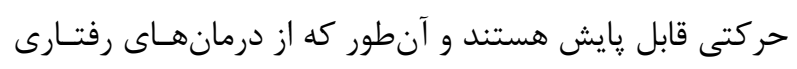

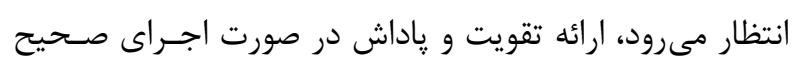

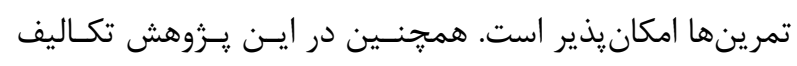

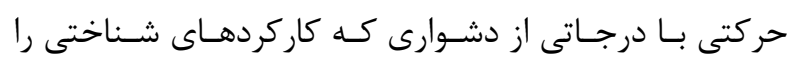

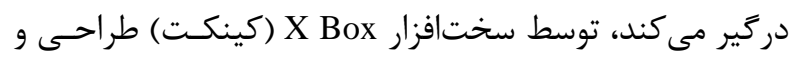

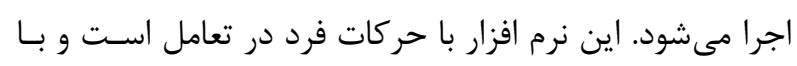

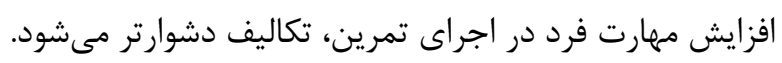

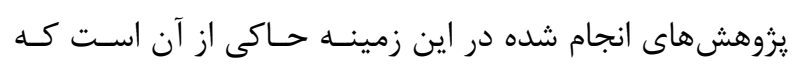

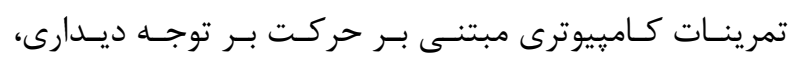

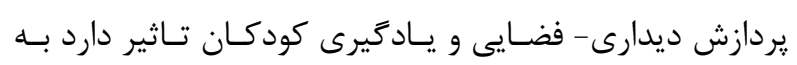

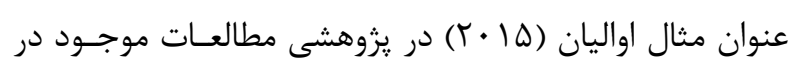

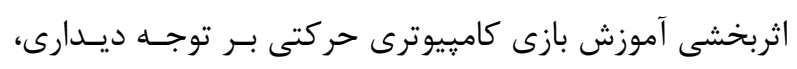

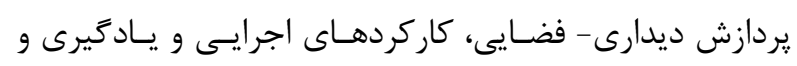

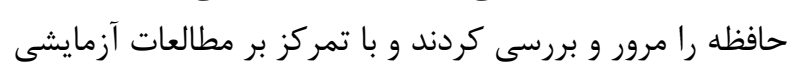
و تركيب اطلاعات رفتارى و عصب- فيزيولوزيكى ارتبـاط علّى كردي

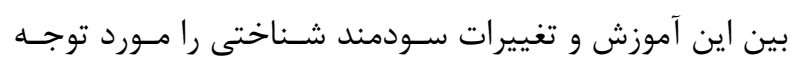

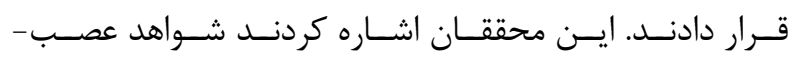

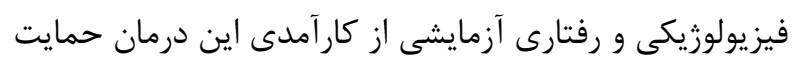

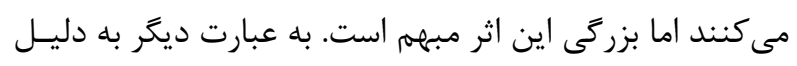

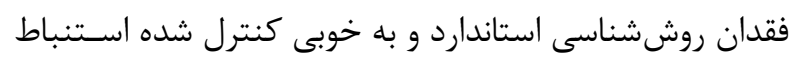

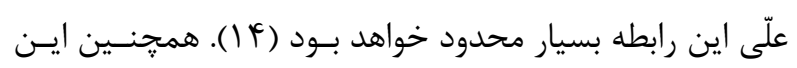

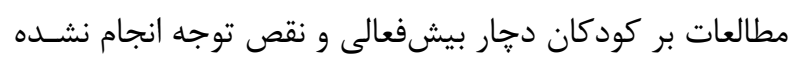

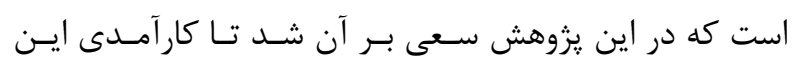

بيشترى شده و يزوهشهاى متعـدنى در ايسن زمينـهـ صـورت

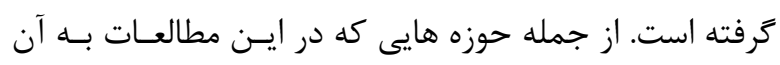

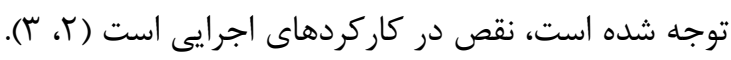

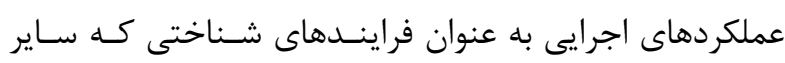

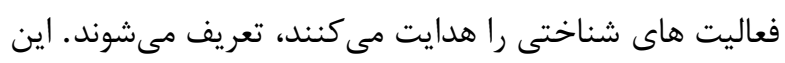

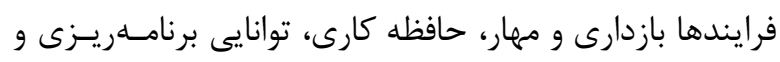

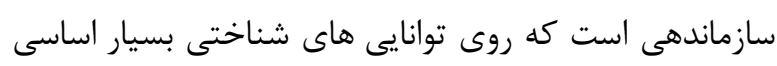

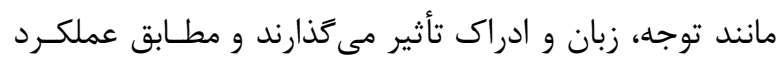

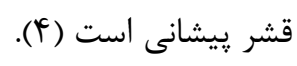

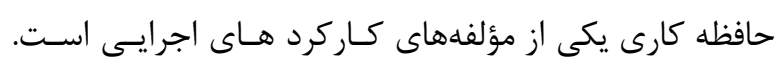

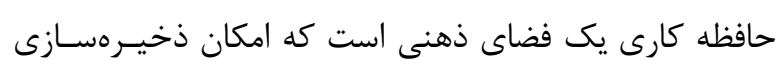

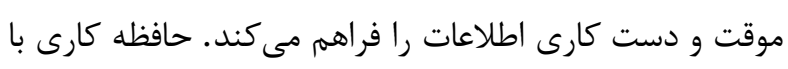

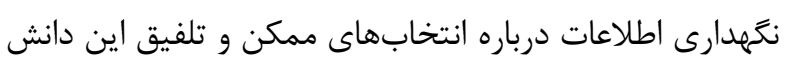

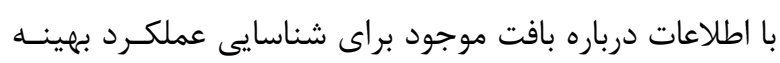

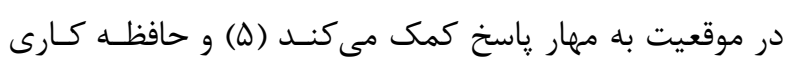

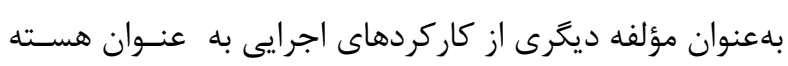
مركزى بسيارى از عملكردهاى شناختى است.

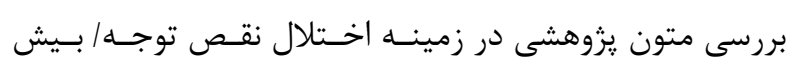

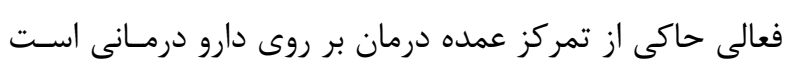

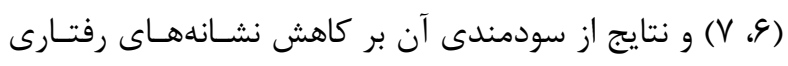

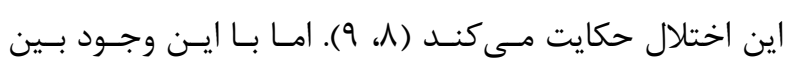

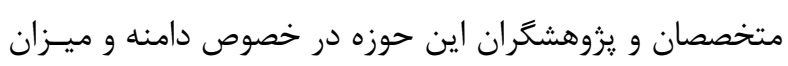

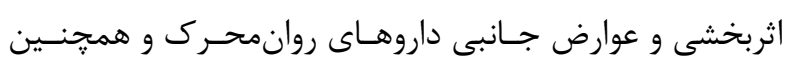

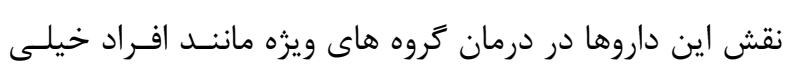

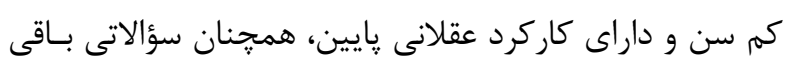

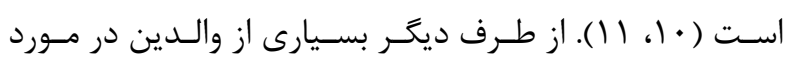

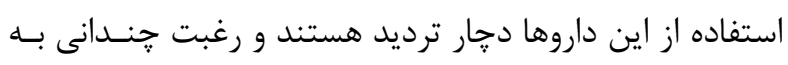

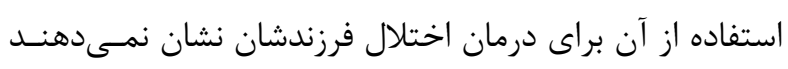

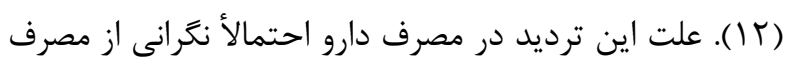

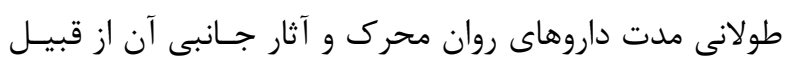

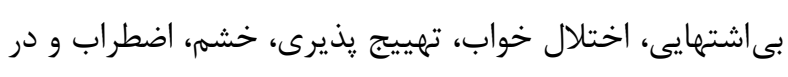

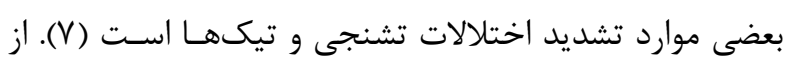

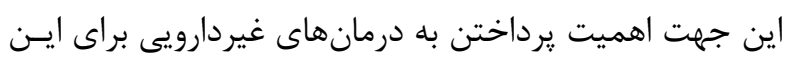

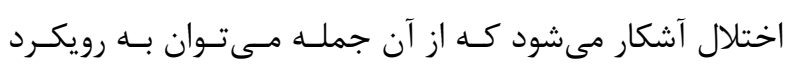

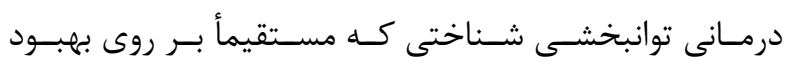

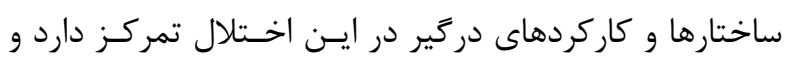
فاقد عوارض جانبى دارو درمانى است، اشاره كرد.

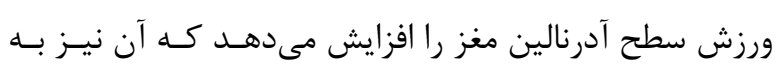

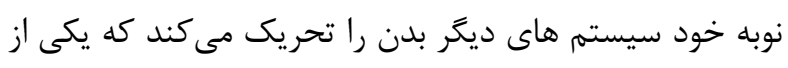

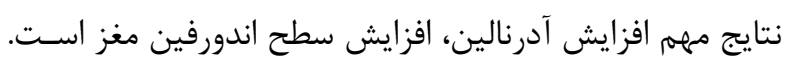




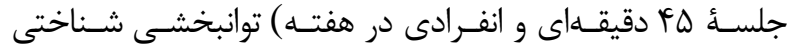
رايانهاى مبتنى بر حركت (برنامه درمانى كارا) را دريافت كردنـد و در اين مدت گروه كنترل تحت هيجزَّنه درمان هاى جـانبى قـرار

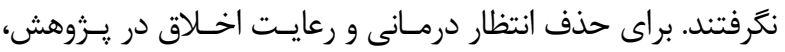
يس از اجراى يزوهش يـك جلسـه تمــرين حركتـى بـراى گَروه

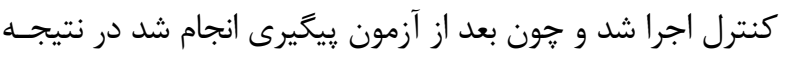

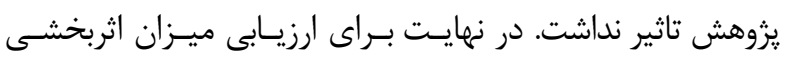
برنامه فوق، بعد از طى ז/ جلسه درمانى، آزمون مذكور بر روى هر دو گروه آزمايش و كنترل اجرا شد. همجٍنين بــراى بررسـى ميـزان

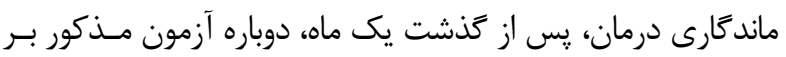
روى هر دو گروه آزمايش و كنتــرل اجـرا شـد. بـهـ منظــور رعايـت

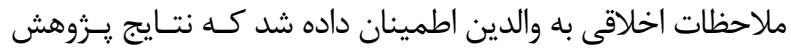

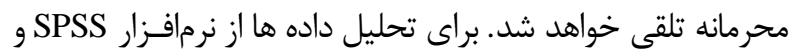

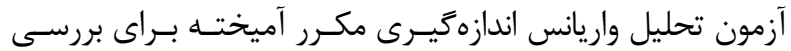

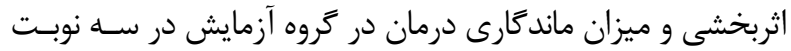

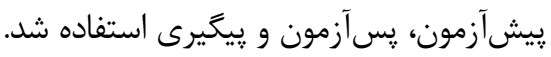

ملاحظات اخلاقى

در اين مقاله، موافقت كميته اخلاق در يـروهش يزوهشـعاه علـوم

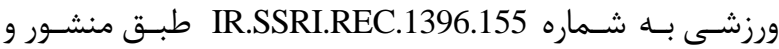
موازين اخلاق يزوهش وزارت علوم و تحقيقـات و فنـاورى گرفتــه شد و مورد تاييد قرار گرفت.

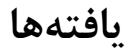

اطلاعات توصيفى به دست آمده از افراد دو گروه آزمايشى و

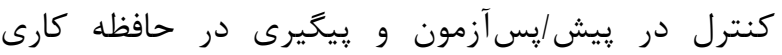
(تعداد پاسخ صحيح و زمان زاسخ در تكليف جند محرك

$$
\text { ييشين) در جدول إن آمده است. }
$$

همان طور كه نتايج جدول I نشان مى دهدي، ميانگين تعداد

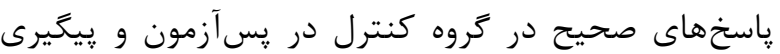
نسبت به پيش آزمون نسبتا ثابت باقى مانده است. در حالى لي كه اين تعداد در گروه آزمايشى افزايش ظاهرى نشان

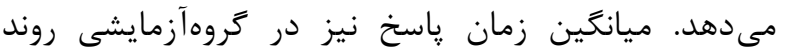
كاهشى و در گروه كنترل روند نسبتا ثابتى را نشان مى دهد. اين تفاوتها ظاهرى هستند و به منظور تعيين معنى دارى آمارى اين تفاوتهاى مشاهده شده آزمون تحليل واريانس

$$
\text { اندازهخيرى مكرر آميخته اجرا شد. }
$$

به منظور اتكا بر نتايج آزمون تحليل واريانس اندازهخيرى

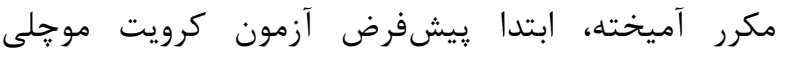
اجرا شد. مقدار آماره (Mauchly's test of sphericity)
درمان مورد بررسى قرار كيـــد. از ايـن رو يـرزوهش كنـونى بــا

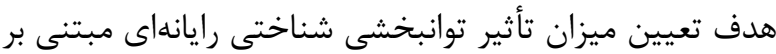

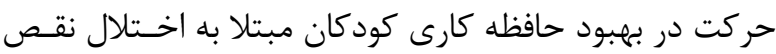
توجه و بيش فعالى انجام شد.

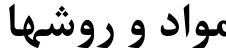

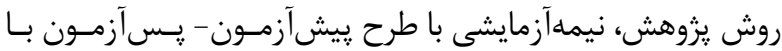

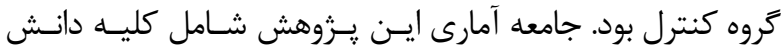

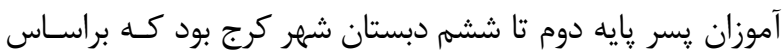

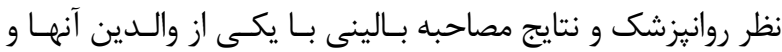
مشاهده و قضاوت بالينى كودك، تشخيص اختلال نارسايى توجه| بيش فعالى را دريافت كردند. اين مطالعه در مهر و آبـانمـاه سـال

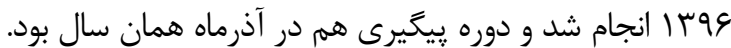
نمونه گيرى ابتدا با روش غيرتصادفى هدفمند و در مرحله بعد بـهـ شيوه تصادفى به گروههاى كنترل و آزمـايش تخصـيص يافت. از

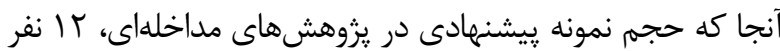
بود (ها)، در يزوهش حاضر براى جلوگيرى از افت آزمـودنىهـا و افزايش توان آزمون، حجم نمونه از ميان دانـشآمـوزان مبـتـلا بــهـ

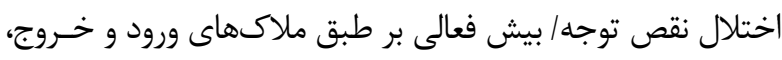

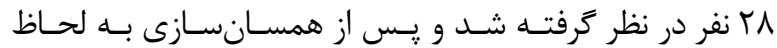
متغيرهاى هوش، سن و شدت علائم به صورت تصـادفى در تَروه

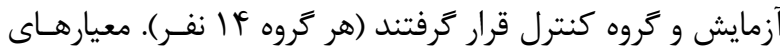

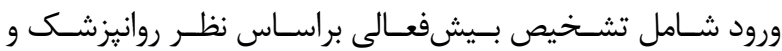

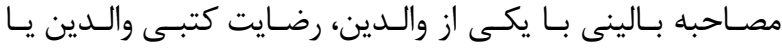
سريرست جهت شركت كـودى در يـزروهش، و معيارهـاى خــروج شامل شركت همزمان كودى در برنامههاى درمانى ديكر، و غيبـت بيش از r جلسه از برنامه درمانى بود. براى شروع كار ابتدا با كسب معرفى نامه بــراى ورود بـه دبسـتان فوق، ملاقات با مسئولين مربوطه صورت گرفت و اطلاعـات مـورد

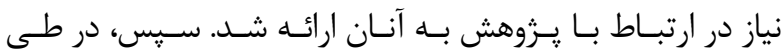
جلسهاى روند كـار و شـيوه درمـان بـراى والـدين تشـريح شـد و رضـايتنامــه كتبـى از والـدين نمونـهـ منتخــب بـراى شـركت در يزوهش اخذ شد و در ادامه كودكان به صورت تصادفى در يكى از گروههاى مداخله و كنترل قرار گرفتند. براى ارزيابى متغير حافظه

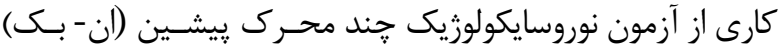

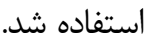
آزمون نوروسايكولوزيك جند محرك يِيشين (ان- بـك) يـك روز قبل از شروع درمان بر روى هر دو گروه آزمـايش و كنتـرل اجــرا

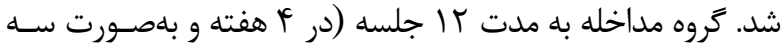


جدول ا. اطلاعات توصيفى كروه آزمايشى و كنترل در يِيش/يسآزمون و پيگيرى در حافظه كارى

\begin{tabular}{|c|c|c|c|c|c|c|c|}
\hline انحراف معيار & خطاى معيار & ميانگين & حداكثر & حداقل & ارزيابى & كروه & متغير \\
\hline & & & & & & & تعداد پِاسخ صحيح \\
\hline G|q & l/AF & IV/AF & ra & 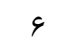 & يِيش آزمون & آزمايشى & \\
\hline$F / r q$ & $1 / 19$ & $T r|G|$ & TV & 11 & يس آزمون & & \\
\hline$r / l f$ & $\cdot \mid \Lambda \Lambda$ & Tr/VV & rq & 11 & ريخيرى & & \\
\hline$V / D F$ & $r / \cdot q$ & $19 / 48$ & rq & r & קِيش آزمون & كنترل & \\
\hline N/rq & T/T & 19 & rq & $r$ & يس آزمون & & \\
\hline \multirow[t]{2}{*}{$V / \Delta \cdot$} & $r / \cdot \Lambda$ & $19 / 41$ & TQ & r & يِيَيرى & & \\
\hline & & & & & & & زمان یاسخ (ثانيه) \\
\hline$\Lambda \varepsilon / \Delta \Lambda$ & $r F / \cdot 1$ & $1 \wedge V / 9 T$ & 411 & $1 \cdot r$ & پِيش آزمون & آزمايشى & \\
\hline$V Y / \cdot \Lambda$ & $19 / 99$ & $19 \cdot / V V$ & 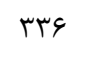 & $\Lambda \Delta$ & يس آزمون & & \\
\hline $0 \cdot 191$ & $|r /| r$ & $|\pi| / 9 \mid$ & $r \Delta \Lambda$ & VT & رِيخيرى & & \\
\hline$F F / D$. & IT/KF & IDT/AF & $r r \Delta$ & $\wedge \varepsilon$ & ֶِش آزمون & كنترل & \\
\hline$\Delta r / V I$ & $|f| 9 \mid$ & $\mid f \cdot / 4 q$ & T\&Q & vq & يس آزمون & & \\
\hline$r N / F q$ & $1 \cdot 191$ & $11 V / 4 \varepsilon$ & $r \cdot q$ & $9 V$ & يیيخيرى & & \\
\hline
\end{tabular}

\begin{tabular}{|c|c|c|c|c|c|c|}
\hline \multicolumn{7}{|c|}{ جدول r. آزمون اثرات درونآزمودنى } \\
\hline توان آمارى & 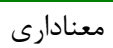 & $\mathrm{F}$ & ميانگين مجذورات & درجه آزادى & مجموع مجذورات & منبع تغييرات \\
\hline .119 & $.1 \cdot .4$ & $\Delta / G T$ & FF/qV & r & $\wedge 9 / 9 \Delta$ & ياسخ صحيح \\
\hline \multirow[t]{2}{*}{ 每 } & $\cdot / \cdot r$ & $V / 19$ & $\Delta V / \Delta q$ & $r$ & $110 / 11$ & باسخ صحيح** كروه \\
\hline & & & $\Lambda / \cdots$ & f. & rNF/T. & خطا \\
\hline
\end{tabular}

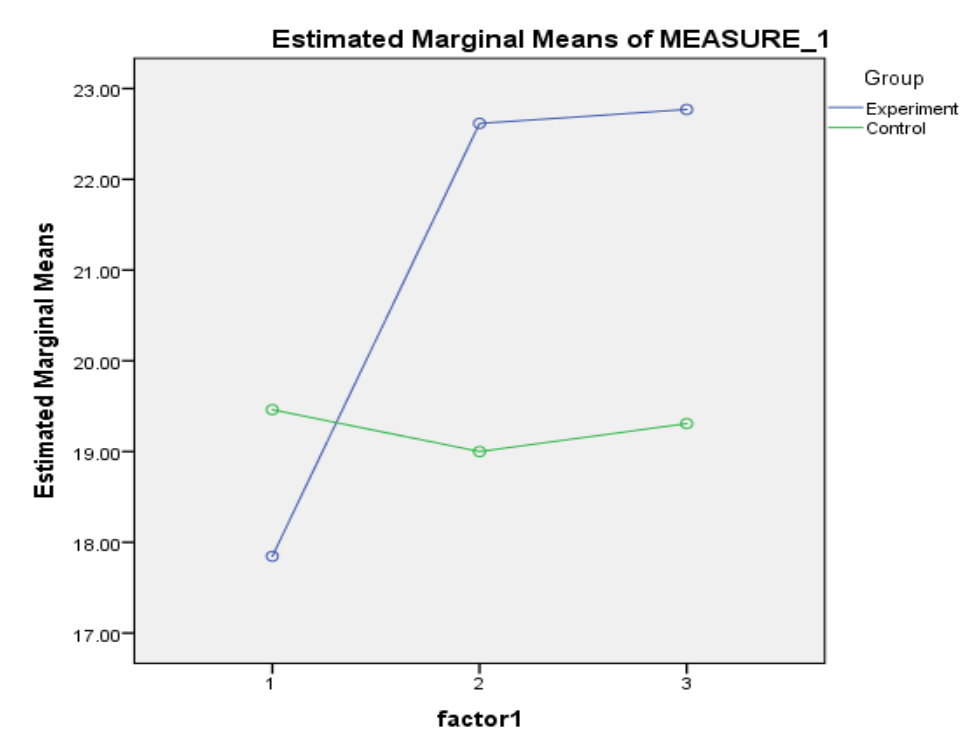

نمودار ا. نمودار اختلاف تعاملى دو كروه در مراحل سهَّانه بيشازمون، پِازمون و بِيكيرى

هين-فلت (Huynh-Feldt Epsilon) استفاده شد. نتايج آزمون اثرات درون آزمودنى در جدول r كزارش شده است.
خى دو اين آزمون برابر با N/TV در درجه آزادى T محاسبه

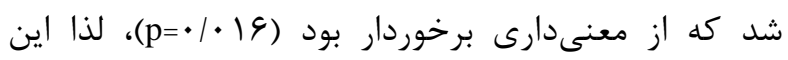

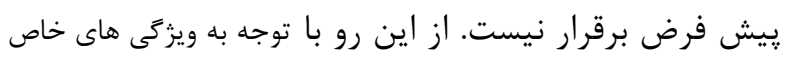

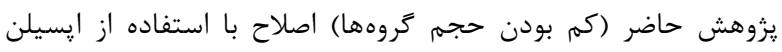




\begin{tabular}{|c|c|c|c|c|c|c|}
\hline توان آمارى & معنادارى & $\mathrm{F}$ & ميانكَين مجذورات & درجه آزادى & مجموع مجذورات & منبع تغييرات \\
\hline$\cdot|r|$ & $\cdot \mid \cdots \cdot 1$ & 1.194 & ITVFN/RG & r & TVEqG/VT & زمان پاسخ \\
\hline \multirow[t]{2}{*}{$\cdot / \cdot r$} & $\cdot / \Delta \Delta$ & $\cdot 19$ & $V 01 / 09$ & $r$ & $10 \cdot r / 1 \Lambda$ & زمان* كروه \\
\hline & & & $\mid r \Delta N / \cdot r$ & $i \wedge$ & G. rAF/VV & خطا \\
\hline
\end{tabular}

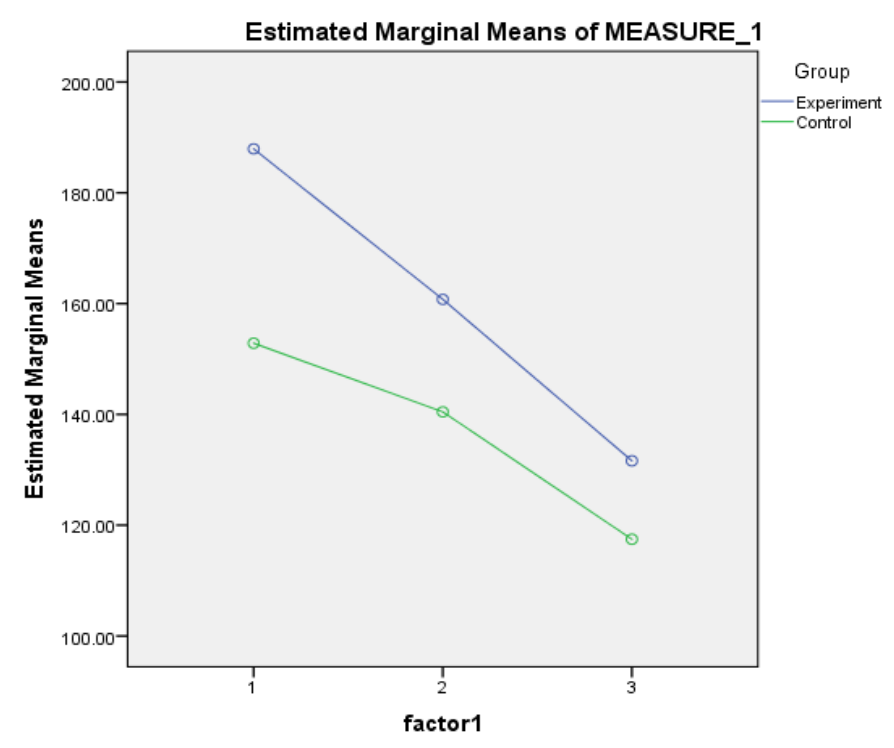

نمودار r. نمودار اختلاف تعاملى دو كروه در مراحل سه كانه پِيشازمون، يسازمون و پِيخيرى

همان گونه كه نمودار 1 نشان مىدهد اختلافهاى تعاملى

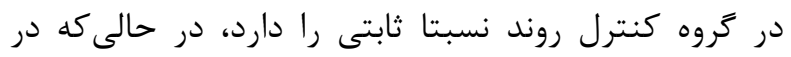

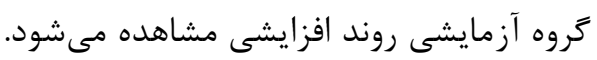

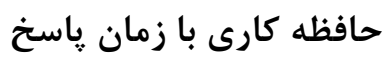

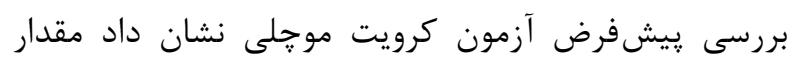

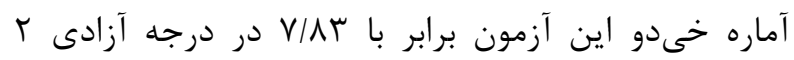

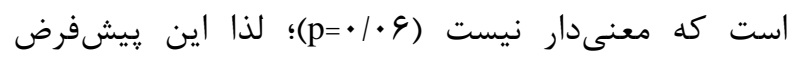

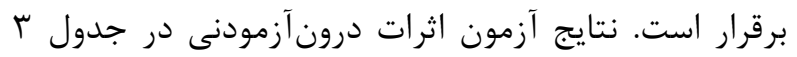
كزارش شده است. نتايج اين آزمون نشان داد بين سه مارت موقعيت در زمان ياسخ

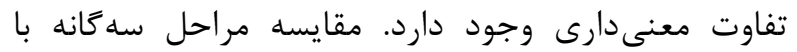

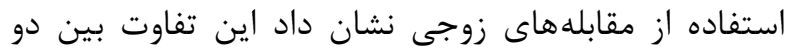

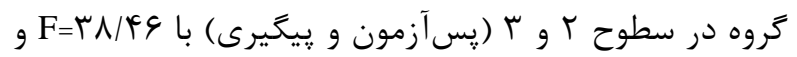

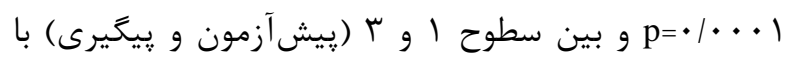
מ

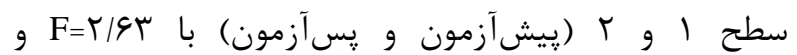

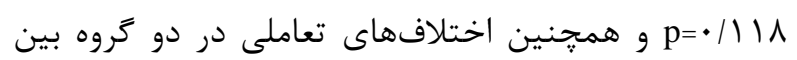

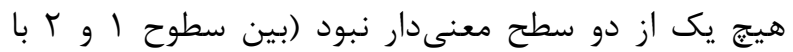

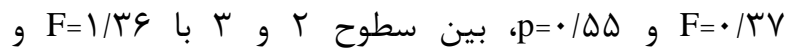

حافظه كارى با تعداد صحيح ياسخ

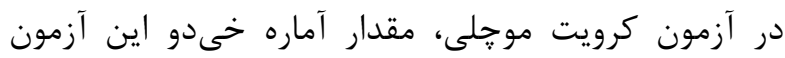

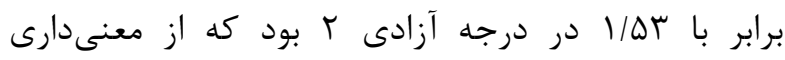

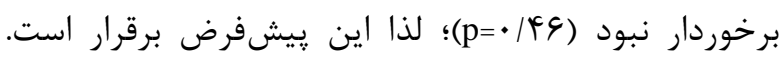

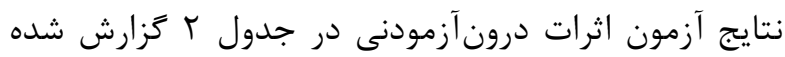

نتايج اين آزمون نشان داد بين سه موقعيت در پاسخ صحيح

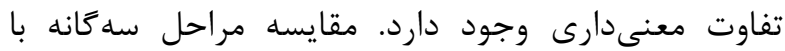

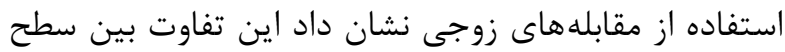

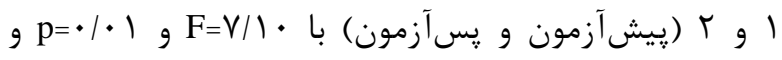

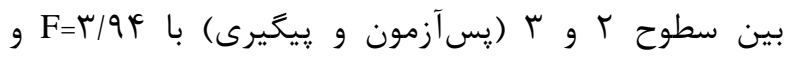

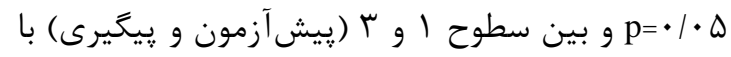

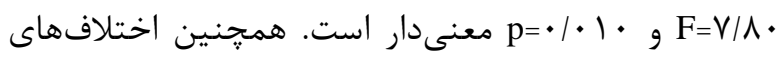

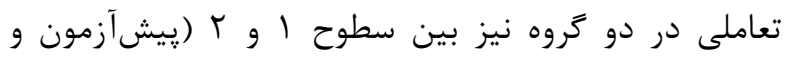

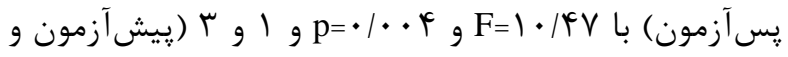

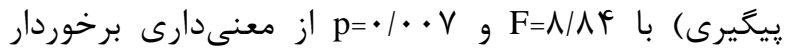

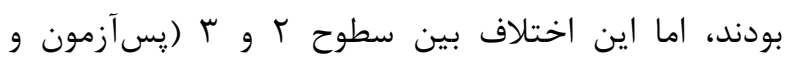
ي קيخيرى) معنى نمودار تعاملى اختلاف دو گروه آمده است (نمودار ()). 
گيرى كردند كه به منظور بهبود بهزيستى عمومى مىتوان

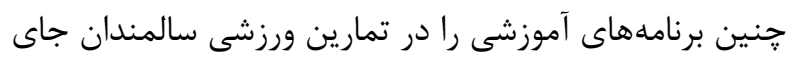

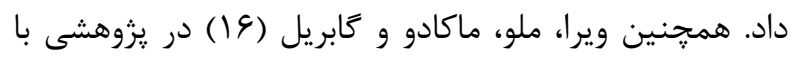

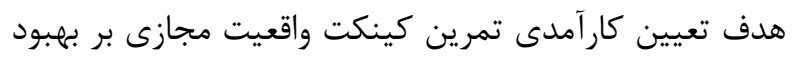

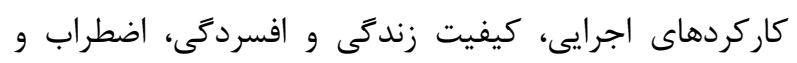

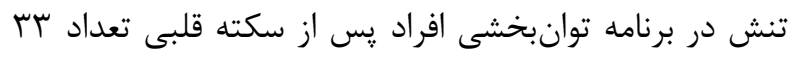

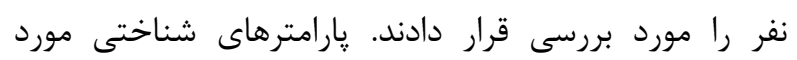

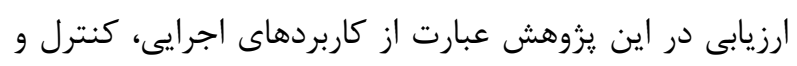

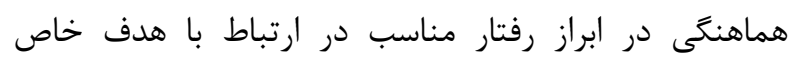
مخصوصا توانايى جابهجايى اطلاعات، حافظه كارى و توجنه

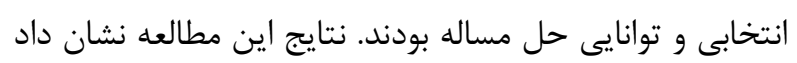

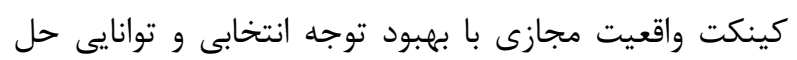

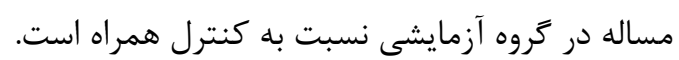

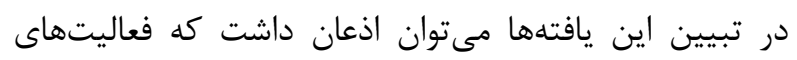

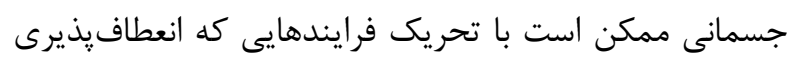

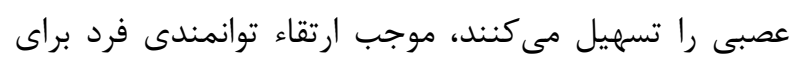

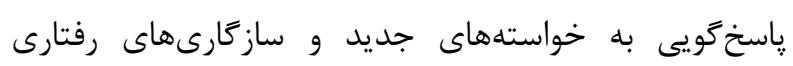

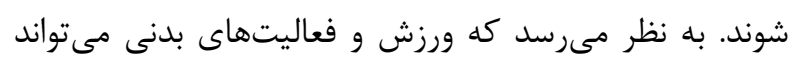

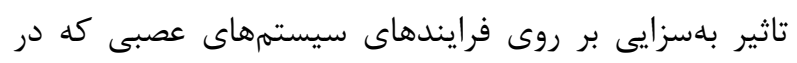

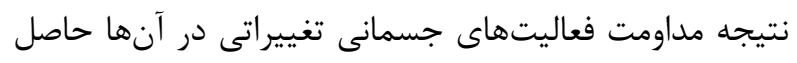

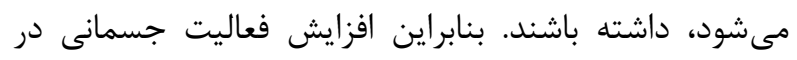
برنامههاى توانبخشى، منجر به افزايش احتمال انعطافيذيرى دئه

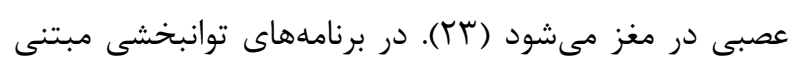

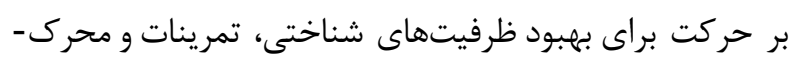

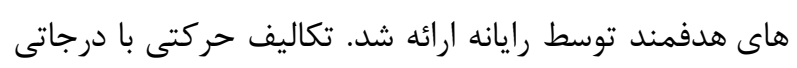

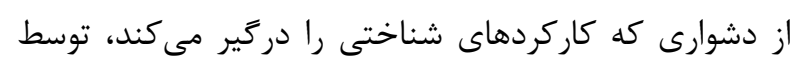

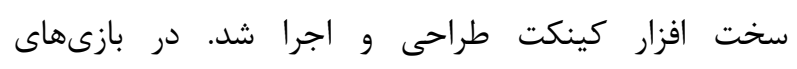

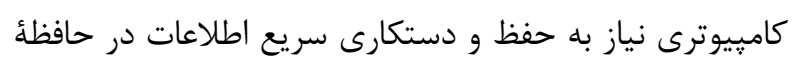

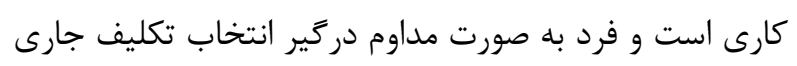

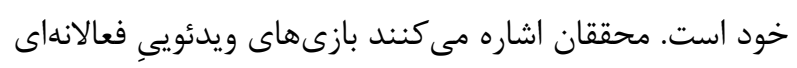

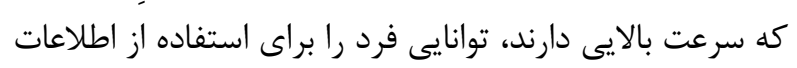

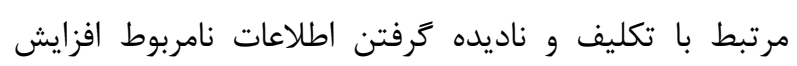

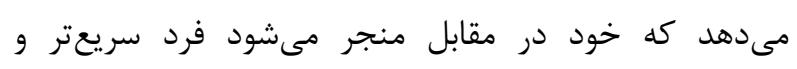

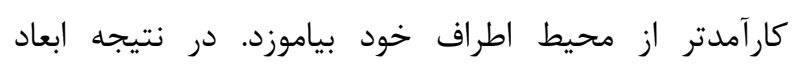

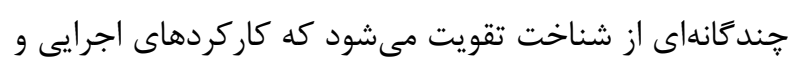

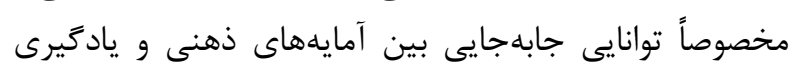

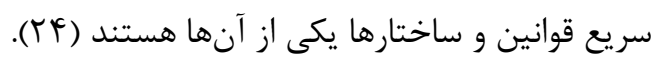

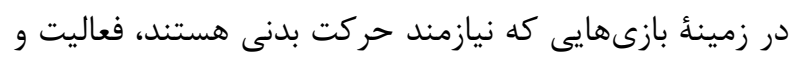

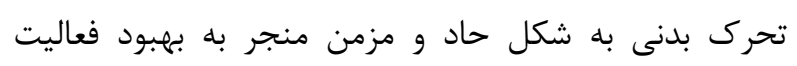

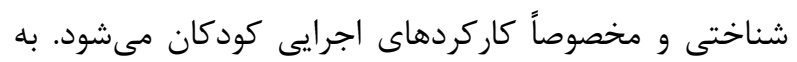

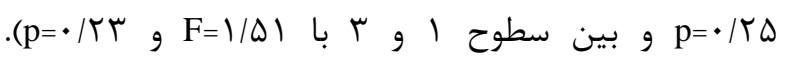

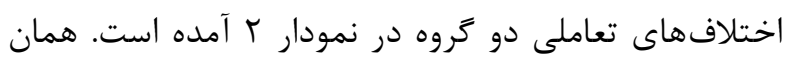

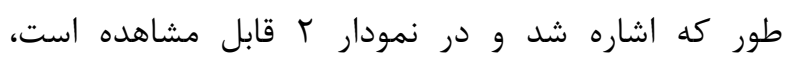

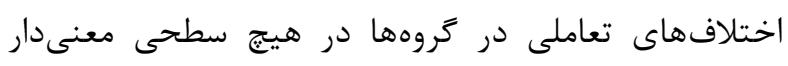

بحث

يزوهش حاضر با هدف بررسى اثربخشى توانبخشى شناختى

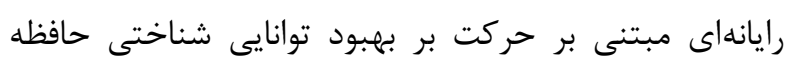

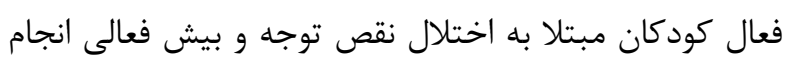
شد. نتايج يزوهش نشان داد كه برنامه توانبخشى شنان شناختى

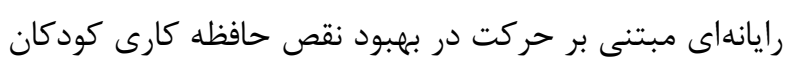

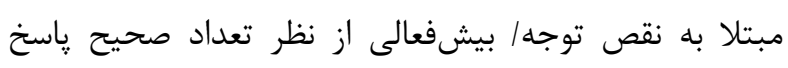

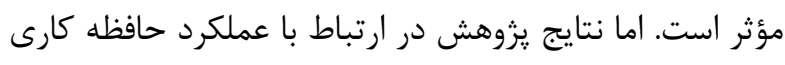

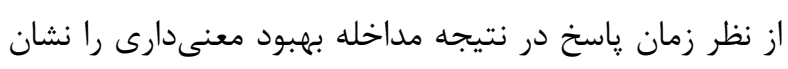

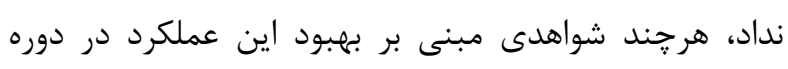

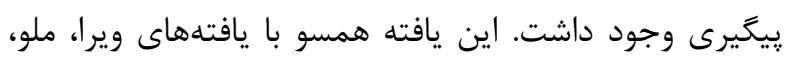

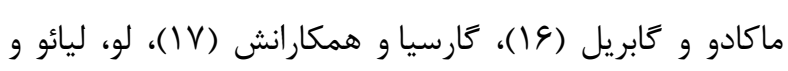

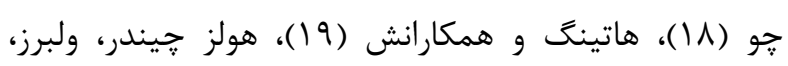

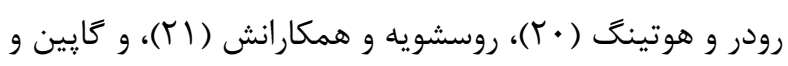
اتينر (YT) است. لو، ليائو و جو (1) (1) با اشاره به سودمندى انجام حركات ورزشى براى حفظ سلامتى و شرايط جسمانى سالمندان و وان إنان

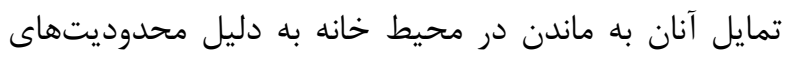

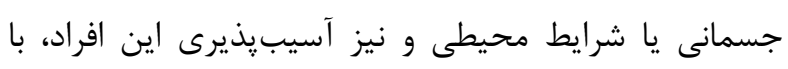

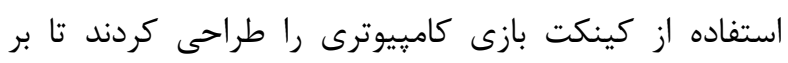

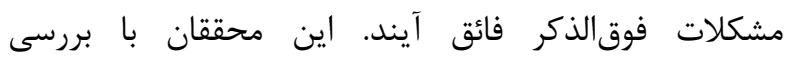

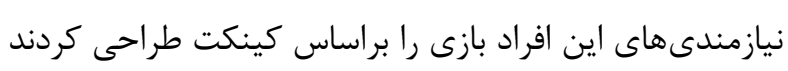

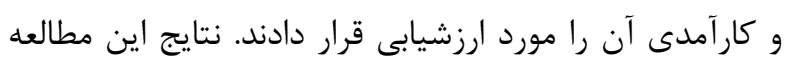

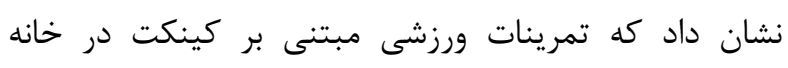

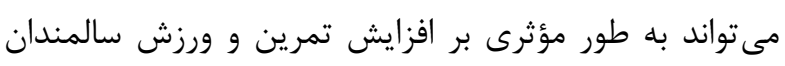

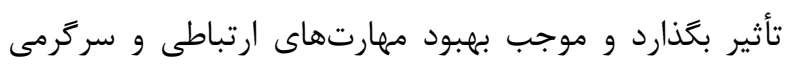

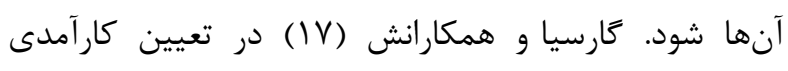

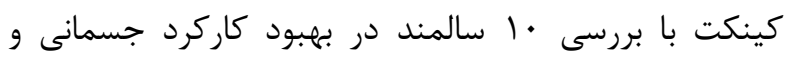

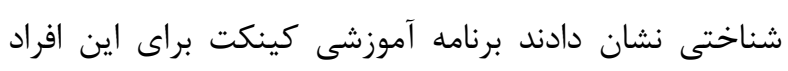

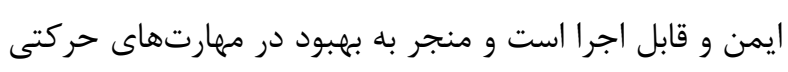

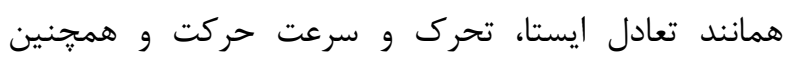

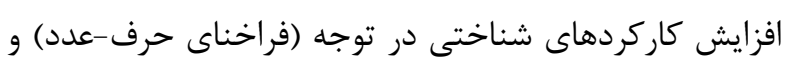

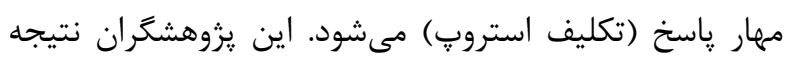


فضايى، حافظه مفهومى و حافظه كارى بهبود جشمخيرى ايجاد مىشود. در يزوهش حاضر هم با تركيب تكاليف شناختى

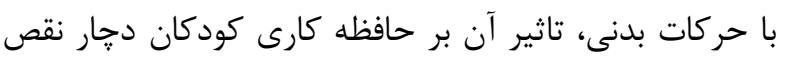
توجه- بيشفعالى مورد بررسى قرار گرفت كه نتايج حاكى از اثربخشى برنامه در بهبود حافظه كارى بود.

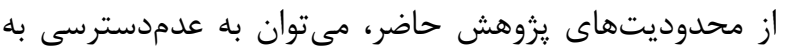

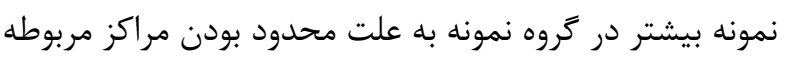

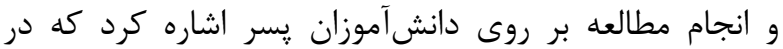
تعميهم نتايج به دختران بايد احتياط كرد. بهتر است در

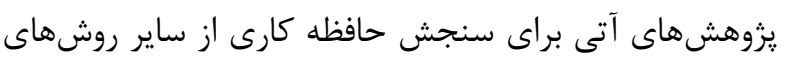
ارزيابى از جمله روشهاى فيزيولوزيكى اشاره كرد. همجنين، مقايسه روش توانبخشى شناختى مبتنى بر حركت با ساير

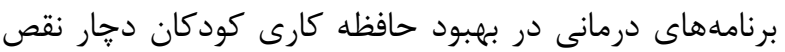

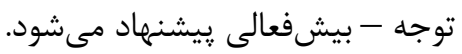

به طور كلى، يزوهش حاضر نشان داد كه توانبخشى شناختى رايانهاى بر پايه حركت در بهبود حافظهى كارى كودكان مبتلا به اختلال نقص توجه و بيشفعالى موثر است. اين اثرات مثبت

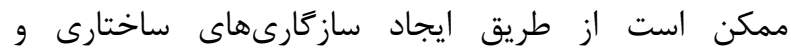
فيزيولوزيكى از جمله افزايش فعاليت هييوكامٍ و در نتيجه ترشح و آزادسازى انتقالدهندهاى سروتونين و دورئين، افزايش سنتز عوامل عصبزايى، افزايش اندازه سلولهاى عصبى، شكليذيرى سينايسى و افزايش انعطافيذيرى عروق مغزى قابل تبيين باشد.

\section{تشكر و قدردانى}

بدينوسيله از همكارى تمام كسانى كـه در ايـن مطالعـه مـا را يارى كردند، صميمانه تشكر و قدردانى مىشود.
علاوه، كودكانى كه تمرين بدنى دارند و ورزش انجام مىدهند، در كاركردهاى اجرايى بهتر عمل مى كنند. در اين خصوص

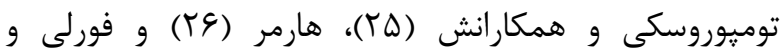
همكارانش (TV) به اثربخشى حركات ورزشى و فعاليتهاى بدنى موزون بر توجه و حافظهى كارى كودكان به ويزه كودكان با ناتوانىهاى عصب- روانشناختى اشاره كردهاند. از سوى ديخر همبستخىهاى نزديكى بين مسيرهاى زيستى بـى زيربنايى متابوليسم انرزى، كنترل حركتى و شناخت هبى وجود دارد كه نشان مى فهند كاركرد مغز زمانى بهينه مىشود كه فرد سطحى خاصّ از فعاليت بدنى با شدت متوسط داشته باشد. از سوى ديخر، طيف وسيعى از تحقيقات اثربخشى تمرينات بدنى در بهبود عملكرد شناختى را در گروههاى سنى مختلف مورد تأييد قرار دادهاند. شواهد ارائه شده توسط وفئن رفامند

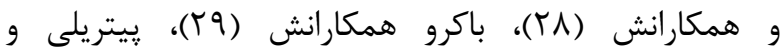

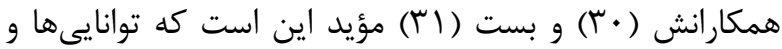
عملكرد شناختى در اثر دورههاى تمرينى بدنى ارتقاء يافته است. مكانيسم عمده اثرات فعاليت بدنى و تمرين بر عملكرد شناختى به سازگًارىهاى ساختارى (Tr) و فيزيولوزيكى (Tr) در دستخاه عصبى مركزى (CNS) نسبت داده مىشود. به

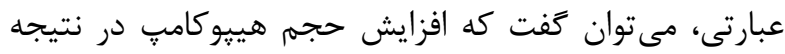
فعاليت حركتى در افزايش و بهبود حافظه كارى نقش دارد. هولزجيندر و همكارانش (• (Y)، در مطالعه خود آموزش ورزشهاى جسمانى و تكاليف شناختى را با هم تركيب كردند و تاثيرات آن را بر روى كاركردهاى حافظه فضايى بزرگسالان مورد بررسى قرار دادند. نتايج مطالعه حاكى از اثربخشى روى لـ تركيب فعاليت جسمانى و شناختى بر كاركرد حافظه فضايى اين افراد بود. در واقع، با در نظر داشتن نقش اساسى و مهرم هييوكامٍ در يادگيرى فضايى و حافظه، فعاليت حركتى باعث افزايش نرونزايى در آنها مىشود و در نتيجه در تكاليف

\section{REFERENCES}

1. Miller M, Hinshaw SP. Does childhood executive function predict adolescent functional outcomes in girls with ADHD? J Abnorm Child Psychol 2010;38:315-26.

2. Haider S, Khaliq S, Ahmed SP, Haleem DJ. Long-term tryptophan administration enhances cognitive performance and increases 5HT metabolism in the hippocampus of female rats. Amino Acids 2006;31:421-5.

3. Verté S, Geurts HM, Roeyers H, Oosterlaan J, Sergeant JA. The relationship of working memory, inhibition, and response variability in child psychopathology. J Neurosci Methods 2006;15:5-14.

4. Brown RT, Amler RW, Freeman WS, Perrin JM, Stein MT, Feldman HM, et al. American Academy of Pediatrics Subcommittee on Attention-Deficit/Hyperactivity Disorder. Treatment of attention-deficit/hyperactivity disorder: overview of the evidence. Pediatrics 2005;115:e749-57.

5. Leroux JR, Turgay A, Quinn D. Advances in ADHD treatment. Can J Diagn 2009;26:49-52.

6. Safer DJ, Zito JM, Fine EM. Increased methylphenidate usage for attention deficit disorder in the 1990s. Pediatrics 1996;98:1084-8. 
7. Sohrabi F. The Effect of Cognitive Rehabilitation of Computer and Psychosocial Drug on Improving Clinical Signs of Children with Attention Deficit Hyperactivity Disorder (ADHD). Contemp Psychol 2012;7:51-60. [In Persian]

8. Schweitzer JB, Lee DO, Hanford RB, Zink CF, Ely TD, Tagamets MA, et al. Effect of methylphenidate on executive functioning in adults with attention-deficit/hyperactivity disorder: normalization of behavior but not related brain activity. Biol Psychiatry 2004;56:597-606.

9. Overtoom CC, Verbaten MN, Kemner C, Kenemans JL, Van Engeland H, Buitelaar JK, et al. Effects of methylphenidate, desipramine, and L-dopa on attention and inhibition in children with attention deficit hyperactivity disorder. Beh Brain Res 2003;145:7-15.

10. Solanto MV, Schachar R, Ickowicz A. The Psychopharmacology of ADHD. In M. Fitzgerald, M. Bellgrove, M. Gill. (eds.), Handbook of attention deficit hyperactivity disorder. West Sussex: John Wiley \& Sons Ltd; 2007:269-314.

11. Halperin JM, Healey DM. The influences of environmental enrichment, cognitive enhancement, and physical exercise on brain development: Can we alter the developmental trajectory of ADHD?. Neurosci Biobehav Rev 2011;35:621-34.

12. Monastra VJ. Clinical applications of electroencephalographic biofeedback. In: Schwartz MS, Andrasik F, Eds. Biofeedback: a practitioner's guide.3rd ed. New York: Guilford Press; 2003. P. 438-463.

13. Kotwal DB, Burns WJ, Montgomery DD. Computer-assisted cognitive training for ADHD: a case study. Behav Modif 1996;20:85-96.

14. Valian V. Bilingualism and cognition. Biling Lang Cogn 2015;18:3-24.

15. Delaware A, ed. Research methods in psychology and educational sciences. Tehran: Viraesh; 2017. [In Persian]

16. Vieira Á, Melo C, Machado J, Gabriel J. Virtual reality exercise on a home-based phase III cardiac rehabilitation program, effect on executive function, quality of life and depression, anxiety and stress: a randomized controlled trial. Disabil Rehabil Assist Technol 2018;13:112-23.

17. Garcia JA, Schoene D, Lord SR, Delbaere K, Valenzuela T, Navarro KF. A bespoke Kinect stepping exergame for improving physical and cognitive function in older people: a pilot study. Games Health J 2016;5:382-8.

18. Liu Z, Liao C, Choe P, eds. An approach of indoor exercise: Kinect-based video game for elderly people. $6^{\text {th }}$ International Conference on Cross-Cultural Design; 2014 Jun 22-27; Heraklion, Crete, Greece. New York: Springer; 2014 Jun. P.193-200.

19. Hötting K, Reich B, Holzschneider K, Kauschke K, Schmidt T, Reer R, et al. Differential cognitive effects of cycling versus stretching/coordination training in middle-aged adults. Health Psychol 2012;31:145.

20. Holzschneider K, Wolbers T, Röder B, Hötting K. Cardiovascular fitness modulates brain activation associated with spatial learning. Neurolmage 2012;59:3003-14.

21. Ruscheweyh R, Willemer C, Krüger K, Duning T, Warnecke T, Sommer J, et al. Physical activity and memory functions: an interventional study. Neurobiol Aging 2011;32:1304-19.

22. Gapin J, Etnier JL. The relationship between physical activity and executive function performance in children with attention-deficit hyperactivity disorder. J Sport Exerc Psychol 2010;32:753-63.

23. Hötting K, Röder B. Beneficial effects of physical exercise on neuroplasticity and cognition. Neurosci Biobehav Rev 2013;37:2243-57.

24. Canas J, Quesada J, Antolí A, Fajardo I. Cognitive flexibility and adaptability to environmental changes in dynamic complex problem-solving tasks. Ergonomics 2003;46:482-501.

25. Tomporowski PD, McCullick B, Pendleton DM, Pesce C. Exercise and children's cognition: the role of exercise characteristics and a place for metacognition. J Sport Health Sci 2015;4:47-55.

26. Harmer CJ. Serotonin and emotional processing: does it help explain antidepressant drug action? Neuropharmacol 2008;55:1023-8.

27. Foley TE, Fleshner M. Neuroplasticity of dopamine circuits after exercise: implications for central fatigue. Neuromolecular Med 2008;10:67-80.

28. Vafamand A, Kargar Fard M, Mortadi SM. Effect of eight weeks aerobic training on serotonin and dopamine levels in women in Isfahan Central Prison. J Isfahan Med Sch 2012;204:1336-48. [In Persian]

29. Baker LD, Frank LL, Foster-Schubert K, Green PS, Wilkinson CW, McTiernan A, et al. Effects of aerobic exercise on mild cognitive impairment: a controlled trial. Arch Neurol 2010;67:71-9. 
30. Pietrelli A, Lopez-Costa J, Goni R, Brusco A, Basso N. Aerobic exercise prevents age-dependent cognitive decline and reduces anxiety-related behaviors in middle-aged and old rats. Neuroscience 2012;202:252-66.

31. Best JR. Exergaming immediately enhances children's executive function. Dev Psychol 2012;48:1501.

32. Thomas A, Dennis A, Bandettini PA, Johansen-Berg H. The effects of aerobic activity on brain structure. Front Psychol 2012;3:86.

33. Morgan JA, Corrigan F, Baune BT. Effects of physical exercise on central nervous system functions: a review of brain region specific adaptations. Mol Psychiatry 2015;3:3. 